ARTIGO

DOI: https://doi.org/10.22481/praxis.v14i30.4375

\title{
VOZES, SENTIDOS E EXPERIÊNCIAS NA EXTENSÃO UNIVERSITÁRIA: O QUE DIZEM AS CRIANÇAS SOBRE O BRINCAR
}

\author{
VOICES, SENSES AND EXPERIENCES IN THE ACADEMIC EXTENSION: WHAT DO \\ THE CHILDREN SAY ABOUT PLAYING
}

\section{VOCES, SENTIDOS Y EXPERIENCIAS EN LA EXTENSIÓN UNIVERSITARIA: LO QUE DICEN LOS NIÑOS SOBRE EL JUEGO}

\author{
Cilene Nascimento Canda \\ Universidade Federal da Bahia - Brasil \\ Leila da Franca Soares \\ Universidade Federal da Bahia - Brasil \\ Giovana Cristina Zen \\ Universidade Federal da Bahia - Brasil
}

\begin{abstract}
Resumo: Este texto aborda a experiência de extensão universitária "Ciranda do Brincar FACED", cujo compromisso foi dialogar e vivenciar o brincar como atividade de cunho estético e cultural, assim como direito fundamental de toda a criança. Na versão apresentada, a experiência extensionista foi organizada com diferentes espaços e formas de produção do conhecimento em Rodas de Conversa, Oficinas, Instalação, Intervenções brincantes e palestras, compostas por palestrantes-crianças, além de espaço para as crianças brincarem livremente em uma escola pública da cidade de Salvador-Bahia. É uma ação que tem como referência o movimento Semana Mundial do Brincar inaugurado pela Aliança pela Infância e diversos parceiros de todo o mundo. A atividade foi tomada como objeto de estudo, tendo como recorte a análise das falas das crianças em uma mesa redonda sobre o brincar, o lugar onde se brinca e de que forma este brincar influencia as representações e entendimentos do lugar onde vivem. Os principais resultados da pesquisa reiteram a ideia de que a criança produz cultura, por meio de formas próprias de criação e de intervenções, se apropriando e transformando o lugar em que vivem. Observou-se também que através do brincar a criança percebe a importância do mundo em seu viver, influenciando suas brincadeiras, podendo inclusive modificar a forma como os adultos vivem a sua ludicidade.
\end{abstract}

Palavras-chave: Brincar. Extensão universitária. Infância.

Abstract: This text deals with the academic extension experience "Ciranda do Brincar FACED" which commitment was to dialogue and to experience as activity aesthetic and cultural, as well as fundamental right of all children. In this version the extensionist experience was organized in distinct 
spaces and ways of knowledge production as Circles of conversation, Workshops, Installation, Biting Interventions and lectures done by children speakers, beyond spaces for children to play freely in a Public School in Salvador, Bahia. It is an action that has as reference the movement World Play Week inaugurated by the Alliance for Children and many partners all over the world. The activity was taken as study object, having as cut-off the analyze of the children's speak in a round-table discussion about playing, the place where they play and how this playing influences the representations and understandings of the place where they live. The main results of the research reiterate the idea that children produce culture, by means of their own ways of creativity and interventions appropriating and transforming the place where they live. It was also observed that by playing the children realize the importance of the world in their living, influencing their jokes, including being able to modify the way the adults deal with their playfulness.

Keywords: Play. Childhood. University extension.

Resumen: Este texto aborda la experiencia del proyecto de extensión universitaria llamado en portugués "Ciranda do Brincar FACED", cuyo compromiso fue dialogar y vivenciar el juego como actividad de cuño estético y cultural, así como derecho fundamental de todo niño. En la versión presentada, la experiencia extensionista fue organizada con diferentes espacios y formas de producción del conocimiento, como las discusiones en debates, talleres, Instalación, Intervenciones didácticas y charlas, compuestas por niños, además del espacio para que los niños jugaran libremente en una escuela pública de la ciudad de Salvador-Bahía. Es una acción que tiene como referencia el Movimiento Semana Mundial del Juego, inaugurado por la Alianza por la Infancia y diversos aliados de todo el mundo. La actividad es tomada como objeto de estudio, teniendo como unidad de análisis el discurso de los niños en una mesa redonda sobre el juego, el lugar donde se juega e de qué forma y cómo ese juego influye en las representaciones y comprensiones del lugar donde ellos viven. Los principales resultados de la investigación reiteran la idea de que el niño produce cultura, por medio de formas propias de creación y de intervenciones, apropiándose y trasformando el lugar en que viven. Se observó también que a través del juego el niño percibe la importancia del mundo en su vivir, influenciando sus juegos, pudiendo incluso modificar la forma como los adultos viven su lúdica.

Palabras clave: Extensión universitaria. Infancia. Jugar.

\section{Introdução}

Entender a extensão universitária como processo educativo, científico e cultural ainda pode significar um desafio para a universidade, principalmente quando envolve a participação efetiva das crianças. Nas orientações do documento intitulado Política Nacional de Extensão Universitária, resultante do Fórum de Pró-Reitores das Instituições Públicas de Educação Superior Brasileiras, reitera-se a indissociabilidade entre ensino, pesquisa e extensão, situando-a como "um processo interdisciplinar, educativo, cultural, científico e político que promove a interação transformadora entre Universidade e outros setores da sociedade" (FORPROEXT, 2012, p. 28). O documento expressa ainda a necessidade de uma escuta sensível aos problemas sociais, bem como ao reconhecimento de que a universidade não é o único espaço de produção de conhecimento. 
A Universidade não pode imaginar-se proprietária de um saber pronto e acabado, que vai ser oferecido à sociedade, mas, ao contrário, exatamente porque participa dessa sociedade, ela deve ser sensível a seus problemas e apelos, sejam os expressos pelos grupos sociais com os quais interage, sejam aqueles definidos ou apreendidos por meio de suas atividades próprias de Ensino, Pesquisa e Extensão. (FORPROEXT, 2012, p. 37).

Projetos de Extensão que envolvam sujeitos na fase adulta são mais fáceis de serem concebidos na perspectiva apontada pelo que determina a Política Nacional de Extensão Universitária. Entretanto, quando se pensa em projetos de extensão que envolvam diretamente as crianças, geralmente as propostas ficam circunscritas a atividades recreativas. A ideia de aprender com as crianças, de ouvir o que as mesmas têm a dizer sobre os problemas sociais ainda não é palatável para os docentes universitários.

Nosso desafio foi pensar em uma atividade extensionista no qual todos pudessem aprender e ensinar, configurando-se dessa forma como um dispositivo de formação para todos os envolvidos, crianças e adultos. Por este motivo, propusemos ao longo do ano de 2016 o Projeto Ciranda do Brincar, da Faculdade de Educação (FACED) da Universidade Federal da Bahia (UFBA). O projeto articula-se ao movimento Semana Mundial do Brincar, inaugurado pela Aliança pela Infância ${ }^{1}$ e parceiros, com o compromisso de difundir informações e experiências, situando o brincar como direito fundamental da criança. Em 2016, o tema "O brincar que encanta o lugar" pretendia:

[...] chamar atenção para a necessidade de se abrir espaços para o brincar. A ideia é que famílias, educadores e adultos em geral mantenham e nunca percam o encantamento de seu olhar sobre a infância, que estimulem e propiciem lugar e tempo para a criança brincar. As atividades da Semana são pensadas para que os pequenos possam, com sua criatividade e imaginação, encantar ruas, praças, casas e escolas. (ALIANÇA PELA INFÂNCIA, 2018)

O Projeto Ciranda do Brincar FACED contou com uma programação diversificada, composta com Palestras, Oficinas, Roda de Conversa, Exposição, Mesa Redonda, além de ações brincantes em comunidades, instituições e escolas municipais parceiras. A realização desse projeto, nesta edição, contou com apoio e articulação entre o Grupo de Estudo e Pesquisa em Educação e Linguagem (GELING), Grupo de Estudo e Pesquisa em Educação e Ludicidade (GEPEL), Grupo de Estudos e Pesquisas em Educação Infantil, Crianças e

1A Aliança pela Infância é um movimento internacional em defesa à infância criado em 1997 por um grupo de educadores. Em 2001, o movimento chega ao Brasil pelas mãos da educadora Ute Craemer.Atualmente a rede que dá suporte à Aliança no Brasil possui uma estrutura multinuclear, formada por 32 núcleos espalhados pelo país. Para maiores informações acessar http://aliancapelainfancia.org.br/ 
Infâncias (GEPEICI), Centro de Investigação, Defesa e Educação da Infância (CRIETHUS), Especialização em Educação Infantil FACED/UFBA, FacedCriançando - Diversão, Arte \& Vídeo.

Entre as atividades realizadas, destaca-se a Mesa Redonda "O brincar que encanta as crianças" mediada pela educadora, brincante e pesquisadora Sálua Chequer e composta por seis crianças entre 5 a 12 anos de diferentes etnias, contextos e classes sociais. Esta atividade se configurou como um dispositivo metodológico desse estudo, no qual as crianças tiveram a oportunidade de relatar suas experiências com o brincar para uma plateia de adultos, formada por estudantes universitários, professores e interessados pela infância, além de outras crianças. O evento foi registrado por meio de fotografias e filmagens que possibilitaram a sistematização dos resultados da pesquisa. Vejamos, a seguir, como aconteceu.

\section{A Mesa Redonda protagonizada pelas Crianças}

A proposta de convidar algumas crianças de diferentes idades, etnias e classes sociais para protagonizar o debate teve o objetivo de compreender como as crianças tecem o lugar em que vivem a partir da experiência do brincar. Para tanto, sugerimos algumas provocações sobre o tema a serem feitas pela mediadora. Entretanto, a partir dos relatos e dos diálogos construídos pelos sujeitos envolvidos, outras questões puderam ser formuladas, porém em todos os momentos a escuta das crianças sobre os modos como brincam e como tecem seus lugares foi priorizada.

Vale destacar que uma atividade de extensão que articula saberes e experiências sob o olhar da criança não é algo recorrente no contexto universitário, por isto implica em alguns riscos. O primeiro risco diz respeito à imprevisibilidade, ou seja, a aleatoriedade do acontecimento da Mesa Redonda em si. Não houve ensaio e nem preparação prévia a respeito do que as crianças deveriam falar, até porque a ideia era deixar que falassem de forma espontânea. Apenas tínhamos como referência o conteúdo das perguntas que seriam realizadas pela mediadora. Dessa maneira, alguns pensamentos inevitáveis tomaram conta das pesquisadoras: e se as crianças não quisessem falar? Como poderíamos estimulá-las a falar? Por quanto tempo elas conseguiriam se manter sentadas em uma mesa de auditório diante uma plateia, em sua maioria, composta por adultos? Esta situação se configuraria como uma experiência para as crianças? 
O segundo risco se caracterizou pelas possibilidades de efetuarmos uma leitura da fala das crianças pelo olhar do adulto, o que poderia resultar em um engessamento da visão sobre a infância. No entanto, na condição de pesquisadoras e professoras universitárias, assumimos este risco, mas buscamos respeitar e valorizar as falas, gestos e posturas das crianças, garantindo a fidelidade na apresentação dos dados fornecidos por elas.

Vale salientar que o primeiro risco foi logo superado, porque as crianças tomaram a palavra, enunciaram análises, exemplificaram, revelaram formas de brincar distintas em relação a um mesmo jogo, sentiram-se livres para discordar do posicionamento de outra criança da mesa. A possibilidade de dispersão ou de timidez foi tranquilamente mediada e a Mesa Redonda, procedimento desta pesquisa, transcorreu naturalmente, conforme os padrões acadêmicos convencionados. Cada criança foi apresentada à plateia com bases nos dados que elas forneceram de como gostariam de ser apresentadas, expressando um pouco da sua identidade pessoal e pertencimento social, a exemplo dos codinomes sugeridos, como "amigo dos animais" e "moradora do Engenho Velho da Federação"2", dentre outros.

Já o segundo risco ateve-se à dimensão ética da pesquisa com crianças que incide diretamente nos procedimentos da análise dos dados com ênfase nas falas delas. Por esta razão, as crianças foram informadas e convidadas a exercerem um lugar ativo na produção e emissão do discurso. Este princípio e estratégia metodológica têm consonância com os estudos de Fernandes (2016):

Considerando o percurso que tem vindo a ser construído nos estudos da criança, em que se valoriza um papel ativo e uma centralidade da criança na pesquisa, há um aspecto que parece reunir consenso entre os investigadores: métodos e técnicas eticamente informadas adicionam valor à pesquisa e, ao mesmo tempo, a solidez metodológica pode melhorar as dimensões éticas na relação de pesquisa com as crianças. (p. 764).

A respeito desta dimensão ética, a autora menciona que os procedimentos da pesquisa devem ser informados para as crianças, para uma maior confiabilidade. Do mesmo modo, se a pesquisa objetiva escutar a criança, é importante evitar a condução restrita do processo de elaboração do pensamento das crianças, "de modo que não haja ruídos ou intromissões que condicionem a recolha da informação" (FERNANDES, 2016, p. 765). E, consequentemente, na análise dos dados, é pertinente evitar inferências ou conduções da análise em categorias estanques sobre o viés somente do adulto.

\footnotetext{
${ }^{2}$ Bairro situado no centro da cidade de Salvador, formando uma forma de comunidade localizado no meio de bairros de classe média alta, como o Rio Vermelho e a Avenida Cardeal da Silva.
} 
Por tais razões, optou-se por estruturar os conteúdos que as crianças selecionaram livremente, com base em seu desejo de fala, sem muitas interferências em seu processo de elaboração da linguagem oral. Isto exige rigor acadêmico, porém um rigor diferente, repleto de sensibilidade, escuta e liberdade da criança, deixando-a à vontade para falar perante uma plateia de adultos que, por si só já pode causar constrangimento, mencionado no risco 1.

As narrativas explicitaram diferentes experiências relacionadas ao brincar e por este motivo, concordamos que "é importante considerar o ponto de vista das crianças nas pesquisas, o que também exige certo abandono do olhar centrado no ponto de vista do adulto" (DELEGADO; MULLER, 2005, p. 353). Para tecermos tal compreensão é fundamental, portanto, desconstruirmos a concepção adultocêntrica de cultura e de linguagem, cedendo espaço para a análise das vozes, gestos e ações das crianças.

\section{O direito de narrar a própria experiência}

A opção pela pesquisa com crianças justifica-se por compreendê-las como sujeitos que têm muito a compartilhar e a contribuir para o entendimento do que é o brincar e da sua relação com o lugar. Por este motivo, elegemos a criança como interlocutora principal dos adultos, mais especificamente, educadores em formação inicial ou continuada, para narrarem as suas brincadeiras mais comuns em seus cotidianos.

As experiências das crianças com o brincar são compostas de sentidos e significados que, ao mesmo tempo, as constituem como sujeitos produzidos e produtores de cultura. As narrativas das crianças sobre as experiências podem se constituir um campo fértil de investigação, para melhor compreender as crianças, suas escolhas, invenções e formas de compartilhar tais informações com o público adulto.

As narrativas infantis revelam sentidos e significados impossíveis de serem conhecidos pelos adultos, senão pela própria interação com as crianças. Pesquisar a experiência humana pressupõe estar com o outro de forma sensível para que o diálogo com esses sujeitos se estabeleça, permitindo assim que o narrado possa ocupar lugares de sentidos. Sobre este aspecto, concordamos que "se as crianças interagem no mundo adulto porque negociam, compartilham e criam culturas, necessitamos pensar em metodologias que realmente tenham como foco suas vozes, olhares, experiências e pontos de vista". (DELGADO; MÜLLER, 2005, p. 353). Este foco nas narrativas infantis constitui-se em um expressivo avanço no campo das pesquisas com crianças, em diferentes áreas, como a 
sociologia, a educação, a antropologia e a filosofia da infância. E é o foco do presente texto, conhecer como as crianças concebem e expressam suas experiências brincantes.

O que é narrado pela criança nem sempre coincide com o que de fato aconteceu, se configura apenas como uma interpretação carregada de significados que ela própria produz para compartilhar com o outro. A experiência humana é um fenômeno complexo, marcado por múltiplas referências, e por este motivo, "não se ex-plica, ou seja, não se fala dela de fora dela, se com-preende, porque, para esse fim, o outro, seu discurso, suas ações e projeções são indispensáveis" (MACEDO, 2015, p.26). Desta forma, o próprio ato de narrar também se constitui em uma experiência, uma situação na qual ela articula os sentidos e significados da situação narrada às expectativas que ela projeta no seu interlocutor.

Os sentidos e significados da experiência do brincar só podem ser compartilhados por aqueles que de fato estão imersos nessa produção. Nesse sentido, "la experiencia es lo que me passa y lo que, al pasarme, me forma o me transforma, me constituye, me hace como soy, marca mi manera de ser, configura mi persona y mi personalidad (LARROSA, 2004, p. 22). O autor afirma também que o sentido é produzido pelo sujeito vivente, de forma própria e singular. Por esta razão, no caso das crianças, a aposta é que as narrativas infantis podem revelar aspectos impossíveis de serem acessados pela simples observação dos adultos. Esse é o ponto fundamental desta discussão, pois existe uma significativa diferença entre conhecer as brincadeiras infantis pela voz do adulto e pela voz das crianças. Nesse contexto, assumimos as narrativas infantis como objeto central deste texto, com o intuito de compreender:

[...]a complexidade das infâncias instigando-nos a investir nos saberes das próprias crianças, não para reafirmar as incapacidades que a elas foram atribuídas, mas para destacar um conjunto de peculiaridades positivas que diferem as crianças dos adultos. (MARTINS FILHO; PRADO, 2011, p. 2).

Com isto, não estamos afirmando que o adulto não possa falar sobre a brincadeira infantil. Ao contrário, muitos pesquisadores, assim como nós, já se debruçaram sobre a criança e o seu brincar. Entretanto, o que nos interessa nesse momento é saber o que a criança, produtora do seu próprio brincar, pode nos revelar sobre os elementos e os sentidos da sua própria experiência.

No caso deste estudo, situado no campo da pesquisa e da extensão com crianças, o fluxo entre o conhecimento de educadores em formação acadêmica e a realidade que as crianças conhecem e vivenciam favorece a ampliação do olhar e do trabalho educativo com a infância. $\mathrm{O}$ entendimento sobre a criança como um ser ativo e portador de direitos e de 
linguagem própria, portanto, produtor de cultura, já bastante discutido em diversos contextos acadêmicos e educacionais, é a base para a constituição dos caminhos da pesquisa. Assim, a pesquisa qualitativa realizada com crianças é tomada como horizonte metodológico deste estudo, que tem como princípio a relação dialógica com o campo empírico mais detidamente no âmbito da extensão universitária. Assim, assumimos o

[...] desafio teórico-metodológico de considerar as crianças atores sociais plenos. Falar das crianças como atores sociais é algo decorrente de um debate acerca dos conceitos de socialização no campo da sociologia. [...]. Essa visão de socialização considera a importância do coletivo: como as crianças negociam, compartilham e criam culturas com os adultos e com seus pares. (DELGADO; MÜLLER, 2005, p. 351).

É justamente neste campo de escolhas, de negociações e de enunciação da fala da criança que se insere a presente pesquisa, com o intuito de compreender como a criança tece o seu lugar a partir da experiência do brincar. $\mathrm{O}$ foco nas brincadeiras produzidas pelas crianças se justifica porque estão situadas em um espaço/tempo de produção de valores, linguagens e saberes. Com isso, busca-se entender o sentido dado ao brincar, garantindo o espaço da voz das crianças nas discussões acadêmicas com educadores em formação.

Na edição do Projeto Ciranda do Brincar FACED de 2016, o tema "O brincar que encanta o lugar" suscitou diversas reflexões. Ao brincar, as crianças tecem o lugar, se apropriam das parcelas do espaço em ritmos diferenciados que se combinam e definem seu caráter. O lugar não é apenas uma definição física, ele define-se a partir de um momento de identificação do sujeito que se vê capaz de estabelecer um limite. O lugar é, portanto, definido por um "quando" e um “onde”. Para Saramago (2011):

O limite não é onde uma coisa termina, mas como os gregos reconheceram, onde uma coisa dá início à sua essência. A delimitação própria dos lugares se vincula principalmente à definição de uma identidade; um lugar é sempre um onde particular, com um caráter próprio, construído ao longo do tempo. Essa identidade é partilhada, muito estreitamente, com os entes que nela se encontram. (p. 19).

Desse modo, podemos afirmar que as crianças se apropriam e reinventam as diversas formas de produção cultural a partir das relações estabelecidas no seu lugar. Por este motivo, garantir às crianças o direito de narrar as próprias experiências do brincar se configura em uma estratégia interessante para compreender a diversidade de relações que tecem cada lugar.

As crianças são atores sociais que se apropriam, reinventam, negociam, compartilham e produzem o seu próprio jeito de estar no mundo, ou seja, a sua própria cultura. A produção 
infantil não é, portanto, a simples imitação ou apropriação direta do mundo adulto. As crianças se apropriam criativamente da cultura adulta para produzir suas próprias culturas. As crianças são coprodutoras da infância, da sociedade e do lugar em que vivem.

Assim, não há como afirmar a existência de uma única cultura da infância. Cada contexto é determinado pela cultura de seu povo. As crianças, mesmo em diferentes contextos, têm a capacidade de recriar e significar o seu lugar a partir do seu próprio modo de ver a realidade. Por este motivo, torna-se imperativo reconhecer a criança como um sujeito cultural, que além de assimilar a cultura, produzi-la e transforma-la, também é capaz de narrar a própria experiência.

\section{Resultados: Vozes, sentidos e experiências brincantes}

A concepção e a execução deste projeto de extensão permitiram o acesso às narrativas das crianças sobre suas experiências com o brincar. Algumas questões nortearam as nossas reflexões: O que as crianças têm a dizer sobre suas experiências brincantes? O que as crianças selecionam para contar sobre as suas brincadeiras? Onde brincam? Há tempo suficiente para brincar? Na visão destes sujeitos, qual o espaço, tempo e lugar para a brincadeira na escola?

As crianças escolheram representar a si mesmas, mas nos papéis de palestrantes. A proposta foi atuar como palestrante, incorporando todos os aspectos que compõe esta prática social: usar uma roupa adequada, falar ao microfone, ter a vez de falar, interromper de forma respeitosa quando necessário, responder as perguntas do público, receber certificado da universidade, manter atenção e concentração sem que isto fosse cobrado.

Assim, desde o primeiro contato com as crianças, esta questão sempre foi enaltecida, dando margem à sua autonomia de pensar e de falar, narrando a sua própria experiência na condição de palestrante. Uma das crianças convidadas a participar da Mesa Redonda demonstrou o seu entusiasmo desde o convite bem como a afirmação de que compreendia o assunto, melhor do que qualquer adulto. Assim pudemos escutar da Criança 1(7 anos), após o interrogarmos:

NÓS - Você topa fazer uma palestra para os adultos, lá na faculdade?

CRIANÇA 1- Hummmm, depende...

NÓS- Depende de quê?

CRIANÇA 1- Do tema, ora!

NÓS - Ah sim, claro. O tema é o brincar. Você pode falar tudo o que sabe sobre o brincar. Pode nos contar onde e como você brinca. Que tal? 
CRIANÇA 1- Ah sim, agora sim. Eu posso sim. Eu sou especialista neste assunto!

Este breve diálogo evidencia a tranquilidade e a segurança para falar do brincar. $\mathrm{O}$ que nos faz pensar, logo de início, que se o tema para conversa diz respeito ao brincar, a criança não apresenta qualquer tipo de hesitação em relação a sua participação. Ela, provavelmente, sabe, tem muito a dizer e demonstra querer dialogar sobre o assunto. A criança 1 se diz especialista quando o assunto é brincar e nos leva, desse modo, a considerar suposições do tipo:

[...] provavelmente as crianças sabem bem mais sobre os adultos e as instituições, embora ainda compreendamos pouco sobre suas idéias acerca das pedagogias, ou sobre o que elas pensam dos adultos e das escolas que criamos pensando nelas e nas suas necessidades. (DELEGADO; MULLER, 2005, p. 357).

Por valorizar a relevância de tais aspectos, nos lançamos a esta escuta das crianças, mediada por perguntas não-estruturadas e comentários livres sobre o que se brinca, atualmente, e do lugar onde se brinca. Buscando criar um clima favorável à troca de informações sobre a experiências do brincar e acolhedor das crianças, a mediadora pegou um cordão (barbante) e um botão (de costura) com furos no meio e disse:

MEDIADORA - Eu gostaria de mostrar uma coisa que brinquei muito no meu tempo. Isso aqui passa alguma informação para vocês? Vocês acham que com isso aqui a gente pode brincar de alguma coisa?

CRIANÇA 5 (7 anos) - Eu acho que pode enfiar pelos buraquinhos. E fecha assim. (faz o gesto de unir duas pontas com os dedos).

CRIANÇA 2 (5 anos) - Aí faz uma correntinha. (que se reconhece como Amigo dos animais), referindo-se a dar um nó nas portas do cordão.

Seguindo a indicação deles, a mediadora mostrou como ela fazia na sua infância, dizendo:

MEDIADORA - E se disser que na minha infância eu brinquei muito com isso com tampinha de garrafa? É o famoso corrupio (e faz o movimento de girar o botão com o cordão no ar) É uma delícia de brincar. Claro que eu trouxe um pra cada porque eu não ia causar confusão (risos entre as crianças). Isso aqui é fantástico e é um brinquedo e hoje mesmo eu levei um na aula e uma criança me disse: "oh pró, uma coisa tão simples e a gente pode se distrair tanto, né?' Uma criança de 8 anos disse isto. Então, é muito legal, cada um vai receber o seu botão e cordão para fazer o seu corrupio". 
As crianças pegaram um barbante e um botão e construíram os seus corrupios, enquanto iniciava-se a conversa. Logo depois uma criança pediu a palavra para expressar o seu pensamento sobre aquela situação:

CRIANÇA 6 (12 anos) - Eu queria dizer que às vezes a gente tem tudo e tem gente que só tem uma tampinha de garrafa para se divertir. Muita gente se diverte com coisas simples. Eu tenho uma colega que ele brinca com uma caneta. Ele fica fazendo sons com a boca, ele fica brincando, tocando (faz movimento de tocar bateria), pulando com a caneta. Eu acho isso muito divertido. É criatividade.

A criança 6 valoriza o ato criativo, faz uma observação sobre uma possibilidade de brincadeira diferente do habitual e, dessa forma, ele reconhece que o colega tem uma habilidade criativa incomum, diferente dos demais sujeitos do cotidiano. Ao escutar o comentário, a criança 5 bate palmas e interfere:

CRIANÇA 5 (7 anos) -Tem gente que ganha um drone de, sei lá, 4 mil reais e depois que brinca, enjoa e larga lá. E tem gente com uma tampinha de garrafa que brinca um ano inteiro, dois anos.

Em seu relato, a criança destaca as possibilidades de brincar com objetos simples que promovem ações não-estruturadas e que absorvem a criança, possibilitando-a brincar durante muito tempo, "um ano inteiro, dois anos", com o mesmo objeto. Assim, convém salientar o valor das brincadeiras livres e ações não-estruturadas com objetos, no sentido das interações e da criatividade, que, segundo a criança, um objeto caro pode não provocar, nem sensibilizar a criança por tanto tempo.

O diálogo a seguir, em torno do que as crianças gostam e costumam brincar, apresenta outros dados relevantes para esta pesquisa:

CRIANÇA 2 (5 anos) - Eu gosto de brincar de pega-pega, de pega-pega altinho, de esconde-esconde e de batatinha 1,2, 3 .

MEDIADORA - De batatinha 1, 2, 3?

CRIANÇA 1 (7 anos) - Não. É batatinha frita 1, 2, 3! Eu gosto também de milhares de brincadeiras. Eu gosto de futebol, baleado, loteria. (...) Cada um tem o seu jeito de falar, tipo, o pega-pega altinho eu chamo de picula.

MEDIADORA- Isso mesmo. E como é esse pega-pega altinho?

CRIANÇA 1(7 anos) - Quem for pego, fica lá no alto. O pega-pega altinho é assim, tipo, a gente sobe a escada, fica lá no alto e o pé pode continuar subindo. Mas para mim isso não faz sentido, só isso.

As falas das crianças demonstram a diversidade de formas de brincadeiras e interações produzidas por elas e evidenciam o seu conhecimento de que o brincar é dinâmico, múltiplo, 
não fixo, ou seja, uma brincadeira pode apresentar nomes diferentes, a depender do lugar e da cultura. A Criança 1 também nos indica que ela pode conhecer uma brincadeira e aprender sobre ela, porém nos afirma que pensa sobre a sua dinâmica e que pode contestá-la e emitir posicionamento quando afirma: “[...], mas para mim isso não faz sentido, só isso”. Desse modo, comprova, de alguma forma, a sua posição ativa diante da realização de um jogo.

Além disso, a fala da Criança 1 exemplifica como a brincadeira pode adquirir modificações no tempo e no espaço, como é o caso da brincadeira "picula" ou "pega-pega" ou "pega-pega altinho". A mudança não está somente no nome, mas também em uma regra específica, sem alterar a estrutura e a forma da brincadeira. Esta questão se confirma quando outra criança faz menção a outra brincadeira similar ao "esconde-esconde" ou "brincar de se esconder”, mas com variações:

CRIANÇA 3 (9 anos) - Eu gosto de brincar de tchauzinho.

MEDIADORA - De tchauzinho? Como se brinca de tchauzinho?

CRIANÇA 3 (9 anos) -Tchauzinho é... é difícil de explicar, mas eu vou tentar. É assim... As pessoas se escondem. Se a pessoa que conta achar a outra escondida, essa pessoa tem que ficar atrás da que conta. Essa pessoa não pode fazer isso nem isso (virando a cabeça para o lado e para o outro, mostrando que a pessoa olha para os lados), senão ela vai poder observar os que vão sair para se esconder. Aí se a pessoa que estiver escondida der tchau para a que está atrás, a pessoa que está na fila pode se esconder de novo. Esse é o objetivo deste jogo.

A criança 3 narra uma variação para brincadeira tradicional de esconde-esconde, endossando a compreensão de que a experiência do brincar é única porque depende dos sentidos e significados atribuídos por cada sujeito e da diversidade de relações que tecem cada lugar. O saber da experiência está relacionado ao:

[...] modo como alguém vai respondendo ao que vai lhe acontecendo ao largo da vida e no modo como vamos dando sentido ao acontecer do que nos acontece. No saber da experiência não se trata da verdade do que são as coisas, mas do sentido ou do sem-sentido do que nos acontece. (LARROSA, 2002, p. 27)

A partir dessa contribuição, podemos então afirmarque o brincar é em si uma experiência, na qual a criança atribui sentidos e significados ao que vai lhe acontecendo e, ao mesmo tempo, estabelece contornos e limites da sua ação no mundo, que definem o seu lugar próprio. Outro momento da Mesa Redonda reafirma esta questão, quando uma das crianças dá uma explicação sobre uma mudança de uma regra específica na brincadeira de pega-pega: 
Criança 2(5 anos)- quando a gente está brincando de pega-pega baixinho, aí eu espero meu colega se afastar e para ele não me pegar, eu corro bem veloz. Criança 1 (7 anos)- Este pega-pega que a gente pega e abaixa ele chama de pega-pega baixinho. E lá na escola tem também o pega-pega tartaruga. A gente tem que fazer igual a uma tartaruga, andar bem devagar; se a gente for rapidão, pegam a gente e já foi; perdeu, playboy.

Observamos, nesse caso, que a regra inverte o sentido convencional do pega-pega, pois vence quem for mais lento e não o mais rápido, como habitualmente. A fala da Criança 1 (7 anos) destaca a possibilidade de inversão dos sentidos e das regras da brincadeira. Eles sabem que se trata da mesma brincadeira, mas experimentada de uma forma diferente, com alguma regra que torne mais difícil ou que precise ativar determinadas habilidades, linguagem ou um conhecimento específico. Nota-se que as crianças se divertem ao falar dessas variações e demonstram sentir prazer em mostrar o quanto conhecem sobre essas transformações que elas produzem em torno do brincar. A respeito disso, Brougère (1998) afirma que se aprende a jogar e aponta para a existência de uma cultura peculiar do jogo que:

[...] torna-o possível e faz dele, mesmo em suas formas solitárias, uma atividade cultural que supõe a aquisição de estruturas que a criança vai assimilar de maneira mais ou menos personalizada para cada nova atividade lúdica. (p.106).

Esta aquisição de estruturas anunciada pelo autor diz respeito a um tipo de aprendizagem de cunho sociocultural que inclui invenção e criação, mas que só é praticado em interação, mesmo em atividades solitárias, como ele menciona. O processo de identificação que a criança realiza, para delinear um limite do "quando" e do "onde" a experiência do brincar acontece, nem sempre ocorre entre pares. Entretanto, mesmo que esteja sozinha, a criança não deixa de ser um sujeito cultural que reinventa as diversas formas de produção cultural próprias do seu lugar. Quando questionadas sobre onde se brinca, as crianças esclareceram que os sentidos atribuídos também dependem da delimitação física e das interações possíveis:

CRIANÇA 2(5 anos) - As primeiras brincadeiras que eu falei, tipo escondeesconde, eu brinco na escola, na hora do recreio, na parte da escada que dá para brincar de pega-pega altinho. Agora, brincadeira tipo cama-de-gato eu brinco em casa mesmo.

MEDIADORA- E você brinca onde?

CRIANÇA 1 (7 anos) - Depende de onde eu estiver. (risos e aplausos da plateia). Lá na escola eu gosto mais é de correr mesmo. Eu também gosto de desenhar em casa, de colocar a minha imaginação para fora com lápis ou com giz. 
A resposta "depende de onde eu estiver" da criança 1, a respeito de onde se brinca, demonstra que a delimitação física pode determinar as escolhas e os sentidos atribuídos pela criança. Por outro lado, nos relatos a seguir fica evidente que os sentidos atribuídos dependem das interações estabelecidas com os pares ou com os adultos.

CRIANÇA 3 (9 anos) - Eu brinco na escola e quando eu chego em casa, eu gosto de brincar com a minha avó. E depois eu desço, brinco mais um pouco; depois eu estudo e só depois eu vou jogar baralho com a minha avó.

CRIANÇA 4 (7 anos) - Eu também gosto de baralho, mas eu jogo com a minha amiga.

CRIANÇA 2 (5 anos) - Eu gosto de brincar com os meus amigos.

As falas das crianças indicam que se brinca em lugares diversos, em casa, na rua e na escola e apontam também para um sentido atribuído ao vínculo afetivo instaurado no ato de brincar. As crianças "produzem a primeira de uma série de culturas de pares nas quais o conhecimento infantil e as práticas são transformadas gradualmente em conhecimento e competências necessárias para participar no mundo adulto" (CORSARO, 2002, p. 114). Este processo de socialização da criança é visivelmente identificado nas falas das crianças, que narram com quem brincam em seu cotidiano.

Durante a realização da Mesa Redonda, observamos também que algumas crianças aproveitaram o momento para narrar seus descontentamentos em relação a atos praticados pelos adultos. A Criança 6, por exemplo, fez uma crítica àquilo que observa no mundo:

CRIANÇA 6 (12 anos) - Eu gostava muito de subir no pé de jambo e ficar lá em cima. Mas eles começaram a cortar os galhos debaixo pra gente não subir e para não pegar jambo.

Ao narrar o episódio, a criança em questão não estava apenas demonstrando sua reprovação em relação ao fato, mas realizando uma denúncia sobre a privação do brincar nos espaços coletivos. A partir desta provocação, as outras crianças começaram a realizar outras denúncias, relacionadas, principalmente, ao tempo destinado ao brincar, especialmente, no recreio escolar. É importante considerar o recreio como um momento significativo para a socialização das crianças, mas muitas vezes, é limitado a um tempo gerenciado, determinado e controlado pelo adulto. O recreio também é aquele instante que se pode brincar, exercer ações livres e estabelecer interações com as demais crianças. Nesse sentido, observamos que não houve um consenso entre elas a respeito da pergunta: você acha que precisaria mais tempo para o recreio da escola? 
Criança 4(7 anos)- Tem uma parte que é assim: na escola,quando a fila tá demorando demais para o lanche, parece não ter tempo para conseguir brincar no recreio.

Criança 3(9 anos)- Eu acho que a gente deveria ter mais tempo de recreio porque lá na escola é só 20 minutos. O quarto ano tem das $3 \mathrm{~h}$ às $3 \mathrm{~h} 25 \mathrm{~min}$ (de recreio). $\mathrm{E} \mathrm{o} 2^{\circ}$ e o $3^{\circ}$ ano das $3 \mathrm{~h} 25 \mathrm{~min}$ até $3 \mathrm{~h} 45$; o $4^{\circ}$ ano fica mais 5 minutos.

Duas falas representam bem a noção de que as crianças têm de que o tempo do recreio é cronometrado e controlado por adultos, conforme problematiza Figueredo (2003):

O recreio - institucionalizado pela escola como tempo de merenda e descanso para o dia escolar que ainda não acabou é desvalorizado como tempo de produção cultural [...]; como um tempo escolar: o recreio teoricamente improdutivo na cultura escolar se transforma em tempo de interações diversas a partir das práticas lúdicas (p. 68).

A fala da Criança 4 (7 anos) demonstra a sua preocupação sobre a possibilidade de não sobrar tempo para brincar no recreio: "quando a fila tá demorando demais para o lanche, parece não ter tempo para conseguir brincar no recreio". A cronometragem do tempo em uma postura de controle, em uma estrutura fabril de fragmentação e vigilância do tempo (FOUCAULT, 2004) é assumida pela escola, estando mais evidente no trecho da fala da Criança 3 (9 anos): "O quarto ano tem das $3 \mathrm{~h}$ às $3 \mathrm{~h} 25 \mathrm{~min}$ (de recreio). E o $2^{\circ}$ e o $3^{\circ}$ ano das $3 \mathrm{~h} 25 \mathrm{~min}$ até $3 \mathrm{~h} 45 \mathrm{~min}$; o $4^{\circ}$ ano fica mais 5 minutos". Mais tempo para o recreio parece ser uma necessidade para as crianças, principalmente as menores, porém algumas crianças discordaram a respeito da necessidade do aumento do tempo para o recreio. Ainda assim, permanece a sensação de que, mesmo no receio, o tempo escolar é controlado pelo adulto. Isto se torna visível nos trechos: "a gente pode brincar um pouquinho" e "Minha mãe sempre dizia que cada coisa tem sua hora. Tem a hora do dever, tem a hora do lanche, do recreio". Para proceder à análise dos dados, retomamos a pergunta e as falas na íntegra: Você acha que na sua escola deveria ter mais tempo para brincar?

Criança 6(12 anos)- Sinceramente não, porque na minha escola, na hora do recreio, enquanto o resto da turma ainda não terminou de merendar, a gente pode brincar um pouquinho.

Criança 4- Não, porque cada coisa tem sua hora. Minha mãe sempre dizia que cada coisa tem sua hora. Tem a hora do dever, tem a hora do lanche, do recreio...

A noção do tempo compartimentado, organizado em tempo "útil” e tempo livre demarcado pela sociedade industrial está impregnado no olhar da escola, do adulto e se espelha na fala de uma das crianças. Em uma análise possível, 
[...] o tempo de escola é determinado por demandas que podem estar diretamente relacionadas ao bem-estar das crianças, ou às necessidades do Estado e da sociedade ou, ainda, à rotina e conforto dos adultos, sejam eles pais ou professores. (CAVALIERE, 2007, p. 118).

Quando as crianças terminaram os seus testemunhos sobre o aumento ou não do tempo de brincar na escola, uma menina ficou muito inquieta na plateia e foi estimulada pelos adultos a falar. Foi cedido espaço na Mesa e microfone para a exposição da sua opinião. Era uma garota pequena, de 7 anos, magrinha, com cabelos compridos sob os ombros e disse de forma envergonhada, mas contundente:

Criança 7 (7 anos)- Eu preferiria ter mais tempo para a gente brincar no recreio, porque é muito pouco!! (fala em tom de reclamação). São só 10 minutos. É isso.

O modo como falou, com certa irritação, demonstrou que ela estava muito insatisfeita com as falas de algumas crianças. Observou-se também a idade como fator imprescindível nesta análise, uma vez que as crianças maiores afirmaram que não precisava aumentar o tempo do recreio da escola. Já as crianças menores expressavam que queriam mais tempo para o brincar, corroborando com a ideia de que a criança pequena tem uma necessidade visível de brincar, conforme reivindica uma delas:

Criança 4(7 anos)- Para mim, não só que tem ser maior o horário do recreio, mas tem que ser maior todas as horas que a gente está brincando.

Foi notório observar que somente uma das crianças situou a experiência do brincar em sala de aula e não apenas no recreio:

Criança 5 (7 anos)- Eu brinco mais na escola, nas aulas de educação física e de dança. Nesta fala, observa-se um lugar pontual para o brincar na escola, no caso o brincar está presente especificamente nas aulas de educação física e de dança. Esta fala evidencia a fragmentação entre teoria e prática, situando o trabalho com o brincar (a ação corporal e livre) em componentes curriculares muito específicos no currículo, historicamente vinculado à prática. As crianças também tocam na ideia de que o brincar e o jogo produzem a distração, a distensão e o prazer, necessários para assegurar a concentração nas atividades de estudo. A fala da Criança 4 marca bem a posição de que é preciso aumentar o tempo do brincar:

Criança 4 (7 anos) - se a gente brincar numa parte mais longa, aí dá mais tempo de fazer as outras coisas da rotina na verdade, eu sempre achei que tinha que ter mais tempo sim. Quando você vai fazer as coisas, aí você acaba 
de chegar na escola, aí já vai fazer o dever, aí você não está com aquela vontade completa para fazer.

Em sua fala, a criança tenta explicar que é preciso ter uma vontade completa para estudar e que se ele brinca mais, essa vontade pode aumentar. E volta a se explicar e aproveita para tecer algumas críticas, ainda, sobre a ação do adulto no recreio:

Criança 4 (7 anos)- Quando você não faz a tarefa é uma coisa que acontece, aí a gente fica sem recreio, mas não deveria acontecer isto, eles podiam fazer de um outro jeito. É uma hora que é para as crianças! Aí quando a gente está brincando vai aquele barulhinho "trimmmmmmm". Acabou o recreio.

Ele diz claramente que os adultos não deveriam suspender o recreio porque uma criança não fez a tarefa. Ele acredita que "eles podiam fazer de um outro jeito", isto é, os adultos poderiam resolver esta questão não retirando o direito do recreio e, sim, criando procedimentos que educam e não retirem o direito da criança à brincadeira. $\mathrm{E}$ arremata que o recreio "é uma hora que é para as crianças!", como sendo este o espaço de ser livre, de brincar e de ser criança. Assim, as narrativas apresentadas endossam a nossa compreensão da criança como ser ativo, criativo e capaz de elaborar a própria brincadeira, dando sentido e significado à experiência.

\section{Considerações finais}

Ouvir as crianças sobre as suas formas de interações e invenções, desvendar um mundo das múltiplas linguagens das crianças, compreender a natureza de suas relações são alguns dos aspectos abordados no presente texto. O projeto de extensão Ciranda do Brincar FACED, de modo articulado com a pesquisa, em sua segunda edição, possibilitou dar voz a crianças a respeito das suas experiências do brincar. A programação desse evento, no ano de 2016, incluiu A Mesa Redonda, intitulada, “O Brincar que encanta o lugar”, composta por uma mediadora e seis crianças de idades e classes sociais distintas, estudantes de escolas diferentes e moradoras de bairros também diferentes na cidade de Salvador.

Considerando a experiência de extensão universitária como campo epistemológico, é possível afirmar a riqueza de projetos e programas empreendidos com o fim de provocar reflexões, realizar ações concretas e produzir conhecimentos a partir das experiências. Nesse sentido, essa experiência extensionista, de maneira geral, revelou que as crianças demonstram opiniões, argumentos, explicações, posicionamentos quando o assunto em pauta é discutir 
sobre o brincar. Sem dúvida, esses sujeitos nos mostraram que conseguem construir diálogos ricos e significativos entre eles, juntamente com a mediadora da Mesa Redonda e com outras crianças e adultos presentes na plateia. Eles não duvidam e nem hesitam sobre os seus saberes e conhecimentos a respeito das brincadeiras. Conhecimentos como esses se configuram como um campo de inúmeras reflexões em articulação com os referenciais teóricos estudados pelos estudantes de licenciaturas presentes na ação de extensão universitária.

É nesse contexto, inclusive, que retomamos a nossa preocupação inicial sobre dois riscos apontados, anteriormente: a imprevisibilidade, aleatoriedade do acontecimento da Mesa Redonda e a possibilidade de uma leitura da fala das crianças pelo olhar do adulto. Quanto ao primeiro risco, as crianças nos mostraram que os nossos receios perderam sustentação, permitindo, dessa forma, dizer que a temática do brincar já é, por si só, estimulante e quanto mais tempo para esse tipo de diálogo, mais a criança tem oportunidade de elaborar a experiência, como também nós, adultos, podemos conhecer melhor a nossa compreensão sobre as infância. Talvez, um ponto fundamental nessa consideração diga respeito à forma e à nossa postura com as crianças que, desde o início, foi de posicioná-las no lugar de sujeito ativo, autônomo e protagonista. Foi importante o fato de os palestrantes terem sido convidados e solicitados sobre o seu desejo de participar ou não do evento, assim como informar e tirar as dúvidas sobre a temática e o formato da Mesa Redonda, antes dela acontecer. As decisões foram diretamente estabelecidas com as crianças e sem intermédio do adulto para que expressassem ou traduzissem a vontade delas.

Com isso, é possível inferir que o segundo risco, anunciado por nós, ou seja, a possibilidade de uma leitura da fala das crianças pelo olhar do adulto, pode, aos poucos, perder seu sentido. Nesse ponto, a forma cuidadosa para encontrar meios extremamente fidedignos em relação à análise das falas das crianças, foi decisiva. Desse modo, os diálogos travados e apresentados, aqui, durante a Mesa Redonda e resgatados através dos áudios e vídeos expressam, sem dúvida, o que os palestrantes realmente disseram.

Dito isso, podemos avançar de forma mais específica em relação ao que foi possível concluir sobre a temática "O brincar que encanta o lugar" sob a ótica das crianças. Vale ressaltar que algumas questões puderam ser formuladas, a partir do conteúdo geral discutido na Mesa Redonda, já anunciadas, anteriormente: $\mathrm{O}$ que as crianças têm a dizer sobre suas experiências brincantes? O que as crianças selecionam para contar sobre as suas brincadeiras? Onde brincam? Há tempo suficiente para brincar? Qual o espaço, tempo e lugar para a brincadeira na escola? 
Desse modo, após realizada a análise das falas das crianças, foi possível apresentar alguns resultados, como: 1) a criança sabe sobre o seu brincar; 2) a criança tem consciência de que o seu brincar muda a depender da sua delimitação física; 3) a criança demonstra compreender que as brincadeiras sofrem variação no tempo e no espaço; 4) as crianças reivindicam um maior tempo para brincar, especialmente no recreio; 5) a necessidade de maior tempo para a brincadeira varia de acordo com a idade.

Assim, é possível afirmar que as crianças têm repertório vasto e é capaz de travar discussões sobre o brincar e seus lugares de produção das suas formas de interagir no mundo. Elas sabem sobre as brincadeiras e que, muitas vezes, pode haver variações em relação à sua dinâmica ou ao nome, mas não se deixa de brincar por esses motivos. Ao contrário, a criança reinventa, constantemente, as formas e as possibilidades de brincar. Por outro lado, as brincadeiras podem mudar e variar de acordo com o tempo histórico e a cultura, assim como pode acontecer em diferentes espaços, seja por conta das limitações físicas do local ou pela companhia que ganhará nesse momento.

As crianças também puderam revelar que podem ensinar uma nova forma de brincar de uma mesma brincadeira quando o outro a desconhece. Há uma disponibilidade para isso e, muitas vezes, parece que essa possibilidade representa ser colocada num lugar de importância, ou seja, de quem sabe e é perito no assunto.

Outro aspecto importante trazido pelas crianças e que influencia no movimento das brincadeiras apresentadas por elas, está relacionado ao tempo. Sem dúvida, o tempo é uma questão importante nesse cenário, pois carrega consigo, muitas vezes, um limite concreto diferente do espaço que também foi citado como propulsor de interferência no brincar infantil. A criança brincar no tempo cronológico determinado e organizado pelo adulto, como referência para o início, meio e fim da sua brincadeira, certamente pode experimentar a sensação de que foram interrompidas na ação de brincar. Ou ainda é possível inferir que, para ela, não foi dada a devida importância ao que é muito importante para ela, como foi possível ouvir de algumas crianças mais novas ao se referirem sobre como o brincar acontece na hora do recreio.

O tempo cronológico que organiza o recreio é revestido por uma lógica que é oposta à do sujeito que está brincando. Isto porque se a brincadeira está possibilitando uma interlocução com quem está imersa nela, possivelmente, não há vontade para finalizá-la em função do ouvir o "barulhinho do trimmmmmm", como a Criança 4 bem nos relatou, 
indicando que o recreio acabou. Na verdade, é chegada a hora de parar de brincar, independente do momento em que estava vivenciando e produzindo sentido à sua brincadeira.

Essa investigação ainda nos revela que há um diferencial importante e que marca uma significativa qualidade em relação aos resultados obtidos, porque foi priorizada a qualidade das falas das crianças, assim como os saberes produzidos se situaram em um contexto de extensão universitária, ou seja, de diálogo com a sociedade, no sentido de troca e de ampliação da discussão pautada. Não há como saber sobre o que as crianças pensam, constroem, aprendem, ensinam, sentem, elaboram, significam sobre o seu brincar se não for através delas próprias. É preciso escutá-las do lugar de quem sabe, um saber, certamente, diferente do adulto, mas muito valioso.

\section{REFERÊNCIAS}

ALIANÇA PELA INFÂNCIA. Disponível em http://aliancapelainfancia.org.br/. Acesso em 05 fev. 2018.

BROUGÈRE, Gilles. Brinquedo e cultura. 8 ed. São Paulo: Cortez, 2010. (Coleção Questões de nossa época, 20)

BROUGÈRE, Gilles. A criança e a cultura lúdica. Revista da Faculdade de Educação, São Paulo: v. 24, n. 2, p. 103- 116, 1998.

CAVALIERE, Ana Maria. Tempo de escola e qualidade na educação pública. Educação e Sociedade, Campinas: vol. 28, n. 100, p. 1015-1035, 2007.

CORSARO, W. A reprodução interpretativa no brincar ao "faz-de-conta" das crianças. Educação, Sociedade e Culturas, Porto-Portugal: n. 17. p. 113-134, 2002.

DELGADO, Ana Cristina Coll; MÜLLER, Fernanda. Sociologia da infância: pesquisa com crianças. Educação e Sociedade, Campinas, v. 26, n.91, p. 351-360, maio/ago. 2005.

Fórum de Pró-Reitores das Instituições Públicas de Educação Superior Brasileiras. Política Nacional de Extensão Universitária. Manaus, 2012.

FIGUEIREDO, Ricardo Carvalho de. $O$ recreio na escola: um estudo sobre a apropriação das práticas lúdicas. Coletânea VI Seminário "O lazer em debate”. Escola de Educação Física, Fisioterapia e Terapia Ocupacional, UFMG - CELAR. Belo Horizonte, 2005, p.68-76.

LARROSA, Jorge. Algumas notas sobre la experiencia y sus lenguajes. In: BARBOSA, Raquel Lazzari Leite (org.) Trajetórias e perspectivas da formação de educadores. São Paulo: UNESP, 2004, p.19-34. 
LARROSA, Jorge. Notas sobre a experiência e o saber de experiência. Revista Brasileira de Educação, Rio de Janeiro: n. 19, jan./abr. 2002, p. 20-28.

MACEDO, Roberto Sidnei. Pesquisar a experiência: compreender/mediar saberes experienciais. Curitiba: Editora CRV, 2015.

SARMENTO, Manuel; GOUVÊA, Maria Cristina Soares de (Org.). Estudos da infância: educação e práticas sociais. Petrópolis, RJ: Vozes, 2008. (Ciências sociais da educação).

SARAMAGO, Ligia. Como ponta de lança: o pensamento do lugar em Heidegger. In: MARANDOLA JR, Eduardo. Qual o espaço do lugar? São Paulo: Perspectiva, 2011.

VYGOTSKY, Lev S. A formação social da mente. São Paulo: Martins Fontes, 1987.

WINNICOTT, Donald. W. O brincar e a realidade. Trad. José Octavio de Aguiar Abreu e Vanede Nobre. Rio de Janeiro: Imago, 1985.

\section{$\underline{\text { SOBRE AS AUTORAS }}$}

\section{Cilene Nascimento Canda}

Doutora em Artes Cênicas; Lotada no Departamento 2 da Faculdade de Educação da Universidade Federal da Bahia - Brasil; Participa do Grupo de Estudos e Pesquisas em Educação, Didática e Ludicidade (GEPEL) do Programa de Pós-Graduação em Educação da FACED/UFBA. E-mail: cilenecanda@yahoo.com.br

\section{Leila da Franca Soares}

Doutora em Educação; Lotada no Departamento 2 da Faculdade de Educação da Universidade Federal da Bahia - Brasil; Participa do Grupo de Estudos e Pesquisas em Educação, Didática e Ludicidade (GEPEL), do Grupo de Estudos e Pesquisas em Educação Infantil, Crianças e Infâncias (GEPEICI) e do Grupo de Estudo e Pesquisa em Educação e Linguagem (GELING), ambos do Programa de Pós-Graduação em Educação da FACED/UFBA. E-mail: leilafrancas@gmail.com

\section{Giovana Cristina Zen}

Doutora em Educação; Lotada no Departamento 2 da Faculdade de Educação da Universidade Federal da Bahia - Brasil; Participa do Grupo de Estudos e Pesquisas em Educação, Didática e Ludicidade (GEPEL) e do Grupo de Pesquisa Formação em Exercício de Professores (FEP), ambos do Programa de Pós-Graduação em Educação da FACED/UFBA. E-mail: giovanacristinazen@gmail.com 